\title{
2 Have natural lake expansion and landscape inundation 3 resulted in mercury increases in flooded lakes of the Great 4 Slave Lowlands (Northwest Territories, Canada)?
}

\author{
5 Joshua R. Thienpont $\cdot$ Joelle T. Perreault $\cdot$ Jennifer B. Korosi • \\ 6 Michael F. J. Pisaric $\cdot$ Jules M. Blais
}

7 Received: 21 July 2017/ Accepted: 19 November 2018

8 (C) Springer Nature B.V. 2018

9 Abstract The inundation of terrestrial vegetation 10 following landscape flooding is an important potential 11 source of mercury to aquatic ecosystems, and may 12 modify mercury cycling, such as through increased 13 methylation. In the Great Slave Lowlands of Canada's 14 Northwest Territories, remarkable landscape flooding 15 has occurred over the recent past, which is the most 16 notable in at least the last several centuries. The 17 potential for this flooding to increase inorganic 18 mercury flux to the lakes of the region has not yet 19 been explored. In this study we used sediment cores 20 from five lakes experiencing a range of recently 21 documented lake expansion to test whether inundation 22 of terrestrial areas has increased the total mercury 23 concentrations in sediments, and resulted in increased 24 total mercury flux. Increases in sedimentary mercury

A1 J. R. Thienpont $(\bowtie) \cdot$ J. B. Korosi - J. M. Blais

A2 Department of Biology, University of Ottawa, Ottawa,

A3 ON K1N 6N5, Canada

A4 e-mail: joshua.thienpont@gmail.com

A5 J. T. Perreault

A6 Department of Geography and Environmental Studies,

A7 Carleton University, Ottawa, ON K1S 5B6, Canada

\section{A8 J. B. Korosi}

A9 Department of Geography, York University, Toronto,

A10 ON M3J 1P3, Canada

A11 M. F. J. Pisaric

A12 Department of Geography, Brock University,

A13 St. Catharines, ON L2S 3A1, Canada concentrations and fluxes in sediment cores from the expanding lakes were relatively small and within the range of non-expanded systems, suggesting that, to date, flooding has not resulted in major total mercury enrichment, unlike in experimental and natural reservoir impoundments. The potential for increased methylation of existing inorganic mercury following expansion was not explored in this paper because methylmercury is dynamic in sediments and does not preserve well, but is an important consideration for future work.

Keywords Climate change - Contaminants . Flooding $\cdot$ Lake sediments $\cdot$ Paleolimnology $\cdot$ Mercury

\section{Introduction}

Increased contaminant exposure of ecosystems through anthropogenic inputs represents a major stressor globally. Mercury $(\mathrm{Hg})$, is a naturally occurring element, released in large quantities by human activities beyond the historical, pre-industrial range. Because of the capacity for long-range transport of mercury in the atmosphere, this contaminant is of particular interest in remote northern regions, which may lack direct sources of anthropogenic pollution. Landscape changes have the potential to alter the movement and mobility of mercury, with concomitant impacts to ecosystems and foodwebs. As mercury

\begin{tabular}{|l|lll|} 
Journal : Medium 10933 & Dispatch : 20-11-2018 & Pages : 10 \\
Article No. : 63 & $\square$ LE & $\square$ TYPESET \\
MS Code : JOPL-D-17-00061 & $\checkmark \mathrm{CP}$ & $\checkmark$ DISK \\
\hline
\end{tabular}


stored in soils is primarily divalent $\mathrm{Hg}$ (II), changing redox conditions, and microbial activity in response to saturation of soils is an important control on total mercury mobility to surface waters, the methylation to bioaccumulating $\mathrm{MeHg}$, and the formation of gaseous $\mathrm{Hg}^{0}$, and thus its potential flux to the atmosphere (Poulin et al. 2016). Hydrological changes resulting in the inundation of terrestrial terrain, for example during the creation of reservoirs in boreal environments, have been shown to result in an influx of $\mathrm{Hg}$ to the newly created aquatic ecosystem in laboratory (Morrison and Thérien 1991), mesocosm (Hall and St. Louis 2004) and whole-lake settings (Hall et al. 2005; Bodaly et al. 2007). The role of large-scale inundation events, such as those associated with impoundment for hydroelectric generation, are well documented sources of $\mathrm{Hg}$ to aquatic ecosystems (St. Louis et al. 2004), which have been shown to be present in aquatic foodwebs at multiple trophic levels (Bodaly et al. 1984; Hall et al. 1998). Natural aquatic ecosystem expansion, for example due to beaver dam impoundment, has also been shown to result in enhanced mercury mobility (Roy et al. 2009). These findings have important implications for future mercury dynamics in northern landscapes, where climate change is resulting in shifts in lake hydrological regimes, including lake expansion and shoreline flooding in some instances (Carroll et al. 2011; Parsekian et al. 2011).

A dramatic example of northern lake expansion and landscape inundation linked to recent climate change can be found on the northwest shore of Canada's Great Slave Lake, in the Great Slave Lowlands and Plains ecoregions of the Northwest Territories (Fig. 1). This landscape exhibits little relief, and has a high proportion of water cover, being dominated by wetlands, small ponds, and many large, shallow lake ecosystems (Ecosystem Classification Group 2009). The region also contains the Mackenzie Bison Sanctuary, established in 1963 as habitat for an ecologically important population of wood bison (Bison bison athabascae), a distinct sub-population, and North America's largest land mammal (Larter et al. 2000). A recent investigation of changes in the Great Slave lowlands region based on Landsat satellite imagery showed that the proportion of the landscape occupied by water in a $10,000 \mathrm{~km}^{2}$ area (including the majority of the bison sanctuary) nearly doubled between 1986 and 2010, and that this increase was correlated with climatic variables (Korosi et al. 2017). While the whole of the
Great Slave Lowlands and Plains has become wetter recently, the response is quite heterogeneous, with some lakes exhibiting extensive ( $>800 \%)$ expansion, while others showed a more muted response (Korosi et al. 2017). Lake sediment records were used to extend the record of lake area changes beyond the observational record, and showed no other periods of lake expansion as large and persistent as those occurring in the last $\sim 25$ years have occurred in at least two centuries (Korosi et al. 2017).

Landscape flooding in the Mackenzie Bison Sanctuary is inundating terrestrial vegetation on the margins of lakes and ponds, drowning the sedges and grasses utilized as the preferred forage by bison, and potentially driving them out of the sanctuary in search of other food sources (Korosi et al. 2017). This widespread flooding of terrestrial material may also be resulting in an influx of mercury to the lake ecosystems, similar to the flooding that occurs with natural impoundments, such as in beaver ponds (Roy et al. 2009), and analogous to hydroelectric impoundments (Teisserenc et al. 2014). Satellite and field-based AQ1 $21_{1}$ observations have shown that the recent flooding is 122 primarily refilling old lake basins, though the lakes 123 have not been as large as their current area in at least 124 the last 200-300 years (Korosi et al. 2017). It is 125 conceivable that, in this hydrologically dynamic 126 landscape where seasonal increases in water levels 127 may have always occurred, but the recent, persistent lake expansion is likely due to climate-related changes, flooded lakes may record a less clear response in mercury change compared to beaver impoundments and reservoirs. We explore this scenario using a paleolimnological approach in a strategically selected series of lakes in this rapidly changing region (Fig. 1). As lake sediments represent a faithful record of changes in total mercury over time (Lockhart et al. 2000), we reconstructed the recent history of mercury accumulation in order to test the hypothesis that landscape flooding in the Mackenzie Bison Sanctuary has resulted in increased mercury concentrations in recently expanded lakes.

Study site

The study region is located within the Great Slave Plains High Boreal, and Great Slave Lowlands Mid Boreal (Level IV) ecoregions (Ecosystem Classification Group 2009). The region has limited relief, is

128

129 130 


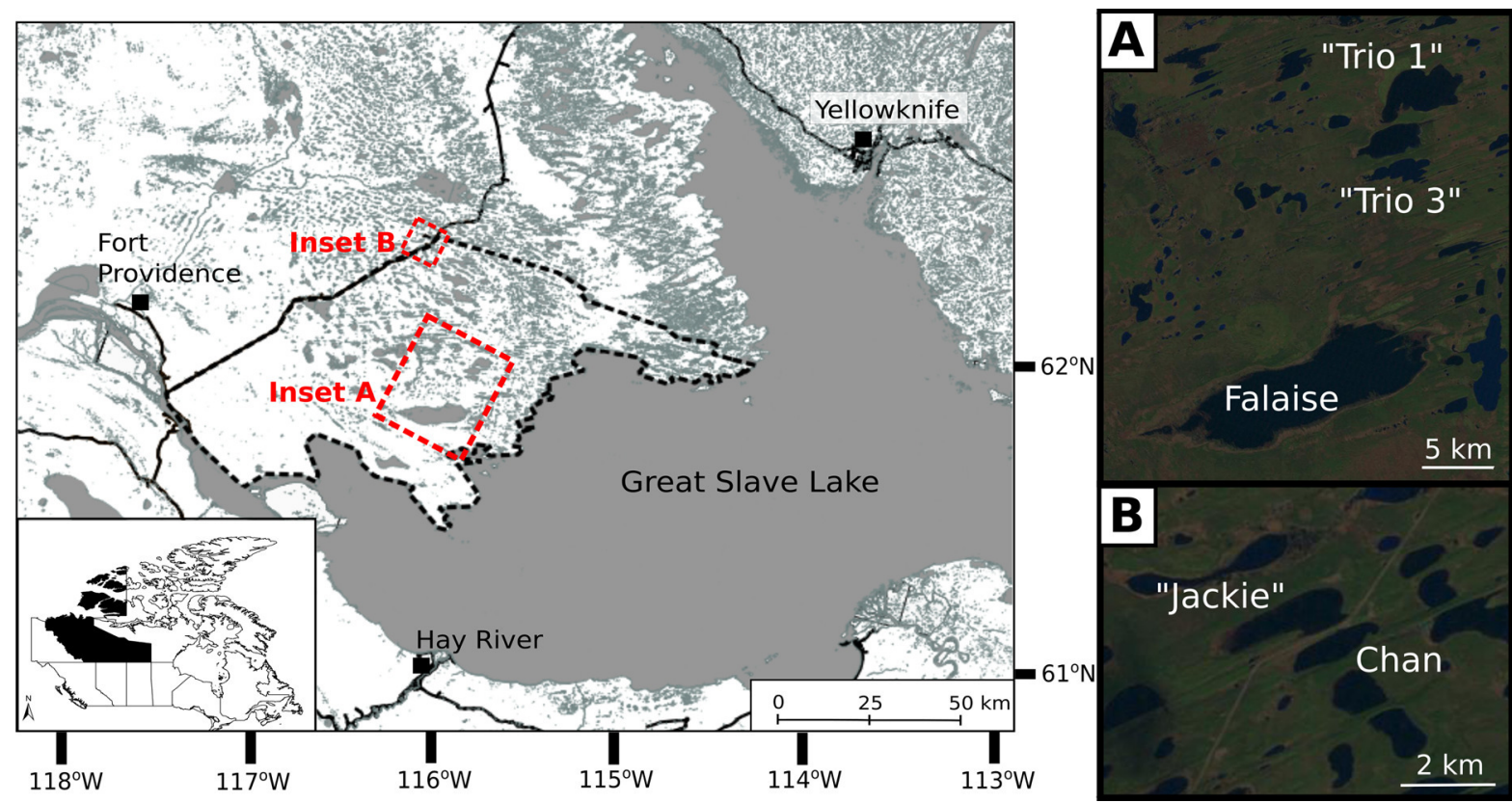

Fig. 1 (a) Map of the study area in the Great Slave Lowlands and Plains region of Canada's Northwest Territories. The area designated as the Mackenzie Bison Sanctuary is delineated with

dominated by wetlands, with a multitude of small marl ponds, and a number of large, shallow lake ecosystems. Bedrock is primarily Cambrian to Devonian aged limestone, sandstone, and dolomite. Surficial geology is composed of a thick mantle of glacial and postglacial deposits greater than $80 \mathrm{~m}$ in depth (Craig 1965), composed of tills and glaciolacustrine deposits from glacial Lake McConnell. Soils are variable throughout the region, including Organic soils in wetland areas, coarse-textured Brunisolic soils especially near beach ridges, and Gleysols adjacent to ponds. Permafrost in the region is sporadic discontinuous, with organic Cryosols associated with peat plateaus (Ecosystem Classification Group 2009).

Five study lakes were selected in the Great Slave Plains and Lowlands ecoregions for analyses (Fig. 1, Table 1). Four of the lakes are located in the core of the Mackenzie Bison Sanctuary (MBS) and to the east of NWT HWY 3, which forms the western edge of the MBS. The fifth lake, "Jackie Lake" (unofficial name) is located on the periphery of the MBS to the west of NWT HWY 3. In order to assess the potential for heterogeneous responses in mercury change associated with varying lake size, the lakes range in area from the largest lake in the MBS, Falaise Lake, to a black dashed line. Landsat images of the study lakes from 2010 are presented in $(a, b)$

Chan Lake, a small lake located along NWT HWY 3 172 (Table 1). In order to test our prediction that landscape flooding has resulted in increased mercury accumulation, lakes that have exhibited recent expansion are compared to sites that have not expanded in the recent past (Table 1; Korosi et al. 2017).

\section{Materials and methods}

Sediment cores were collected from the deepest location in each of the five lakes through the latewinter ice in March of 2012, using a Glew-type gravity corer (Glew 1989). Sediment cores were extruded into $0.5 \mathrm{~cm}$ intervals using a Glew-type vertical extruder (Glew 1988), and kept $<10{ }^{\circ} \mathrm{C}$ during transport and prior to analyses. The sediment cores were the same as utilized for the analyses presented in Korosi et al. (2017), which included determination of total organic carbon, nitrogen content, $\mathrm{C}: \mathrm{N}$ elemental ratio, and ${ }^{13} \mathrm{C}$ and ${ }^{15} \mathrm{~N}$ stable isotope analyses. Selected intervals were prepared for ${ }^{210} \mathrm{~Pb}$ and ${ }^{137} \mathrm{Cs}$-based radioisotopic dating using gamma spectroscopy, with details presented in Korosi et al. (2017), with the constant rate of supply (CRS) model used for sediment age
179

180

181

182

183

184

185

186

187

188

189

190

191

192

193

\begin{tabular}{|l|lll|}
\hline Journal : Medium 10933 & Dispatch : 20-11-2018 & Pages : 10 \\
Article No. : $\mathbf{6 3}$ & $\square$ LE & $\square$ TYPESET \\
& MS Code : JOPL-D-17-00061 & $\checkmark_{\mathrm{CP}}$ & $\checkmark$ DISK \\
\hline
\end{tabular}


Table 1 Study lake locations, recent surface area and Landsat-derived area change (\%) between 1986 and 2010 (from Korosi et al. 2017)

\begin{tabular}{lllll}
\hline Lake & Latitude $\left({ }^{\circ} \mathrm{N}\right)$ & Longitude $\left({ }^{\circ} \mathrm{W}\right)$ & 2010 surface area $($ ha $)$ & Percent change 1986-2010 $(\%)$ \\
\hline Falaise & 61.47642 & 116.15280 & 5637.6 & +824 \\
"Trio 1" & 61.64026 & 116.05184 & 1036.4 & +462 \\
"Trio 3" & 61.59762 & 116.07063 & 306.4 & +20 \\
"Jackie" & 61.89678 & 116.55987 & 151.0 & +313 \\
Chan & 61.89079 & 116.54170 & 66.2 & +51 \\
\hline
\end{tabular}

Lake names in quotation marks are unofficial

194 determination (Fig. 2). Modelled errors associated 195 with the dates corresponding to the observed recent 196 lake expansion were low (less than 5 years for dates 197 since 1950). Freeze-dried and homogenized samples 198 were analyzed for total mercury by thermal decom199 position with gold trap amalgamation and cold vapour 200 atomic absorption spectrometry (CV-AAS) using a 201 Nippon Instruments SP-3D mercury analyzer with a 202 detection limit of $0.01 \mathrm{ng}$ per sample size. Required 203 sample masses ranged from 17 to $30 \mathrm{mg}$ (dry weight). 204 Measurement accuracy was estimated by running 205 blanks and calibrated with MESS-3 (91 $\pm 9 \mathrm{ng} \mathrm{g}^{-1}$, 206 Natural Resources Canada) as reference material, 207 every 10 samples. Results of mercury concentration 208 analyses were determined per unit mass dry sediment 209 weight, as well as per unit mass of organic carbon. As 210 the concentration of organic carbon throughout the 211 sediment cores did not change significantly (Korosi 212 et al. 2017), the profiles of total mercury per unit 213 organic carbon did not differ from per unit dry weight, 214 and as such only the latter are discussed below. 215 Mercury fluxes to lakes were estimated based on the 216 modelled sedimentation rate determined via the CRS 217 model utilized for sediment chronology development 218 for the sediment cores for all five lakes (Fig. 2).

\section{Results}

Changes in sedimentary mercury concentrations
The concentration of total mercury ( $\mathrm{THg}$ ) in the sediment core from Falaise Lake showed only small variations over time (Fig. 3). Over the recent past, a relatively small magnitude increase in $\mathrm{THg}$ was observed since the mid-1980s, which was strongly correlated to the marked ( $>800 \%)$ increase in lake area (Spearman rank correlation, $n=7, \mathrm{r}_{\mathrm{s}}=0.94$, $p<0.001$ ) (Fig. 3). The highest concentration recorded in Falaise Lake, $\sim 33 \mathrm{ng} \mathrm{g}^{-1}$ in the surface sediment interval, was well below the sediment quality guidelines for the protection of aquatic life set at $170 \mathrm{ng} \mathrm{g}^{-1}$ by the Canadian Council of Ministers for the Environment (CCME 1999) The THg concentration in "Trio 1" Lake increased slightly from the earliest part of the record $(\sim 1850)$ until $\sim 1950$, after which it decreased, despite the increase in lake surface area observed for this system (Fig. 4a). "Trio 3" Lake recorded the highest magnitude $\mathrm{THg}$ concentration in the sediment cores in this study (Fig. 4b). The concentrations of THg in "Trio 3" decreased after $\sim 1975$, during which time the lake area exhibited some fluctuation, but no directional change (Fig. 4b). In "Jackie" Lake, $\mathrm{Hg}$ concentration exhibited a rapid increase after $\sim 1990$ from $\sim 25$ to $\sim 45 \mathrm{ng} \mathrm{g}^{-1}$, which tracked closely the timing and direction of lake area increase inferred from Landsat imagery (Fig. 5a). In Chan Lake, $\mathrm{Hg}$ concentration showed several small magnitude changes throughout the period represented by this sediment core, which were not related to lake area, which increased slightly $(\sim 51 \%)$ over the period of record (Fig. 5b). Correlations were not conducted for the latter four lakes due to a low number of samples that had overlapping area estimates and mercury determinations. All sedimentary total mercury values were below the CCME sediment quality guidelines.

Changes in mercury flux

The total mercury flux to the sediment in Falaise Lake decreased after $\sim 1940$, until the onset of lake

\begin{tabular}{|l|lll|}
\hline Journal : Medium 10933 & Dispatch : 20-11-2018 & Pages : $\mathbf{1 0}$ \\
& Article No. : $\mathbf{6 3}$ & $\square \mathrm{LE}$ & $\square$ TYPESET \\
& MS Code : JOPL-D-17-00061 & $\checkmark \mathrm{CP}$ & $\checkmark$ DISK \\
\hline
\end{tabular}


Fig. 2 Radioisotopic activity and constant rate of supply modelled sediment age, along with associated error, for the five sediment cores from the Great Slave Lowlands and Plains region

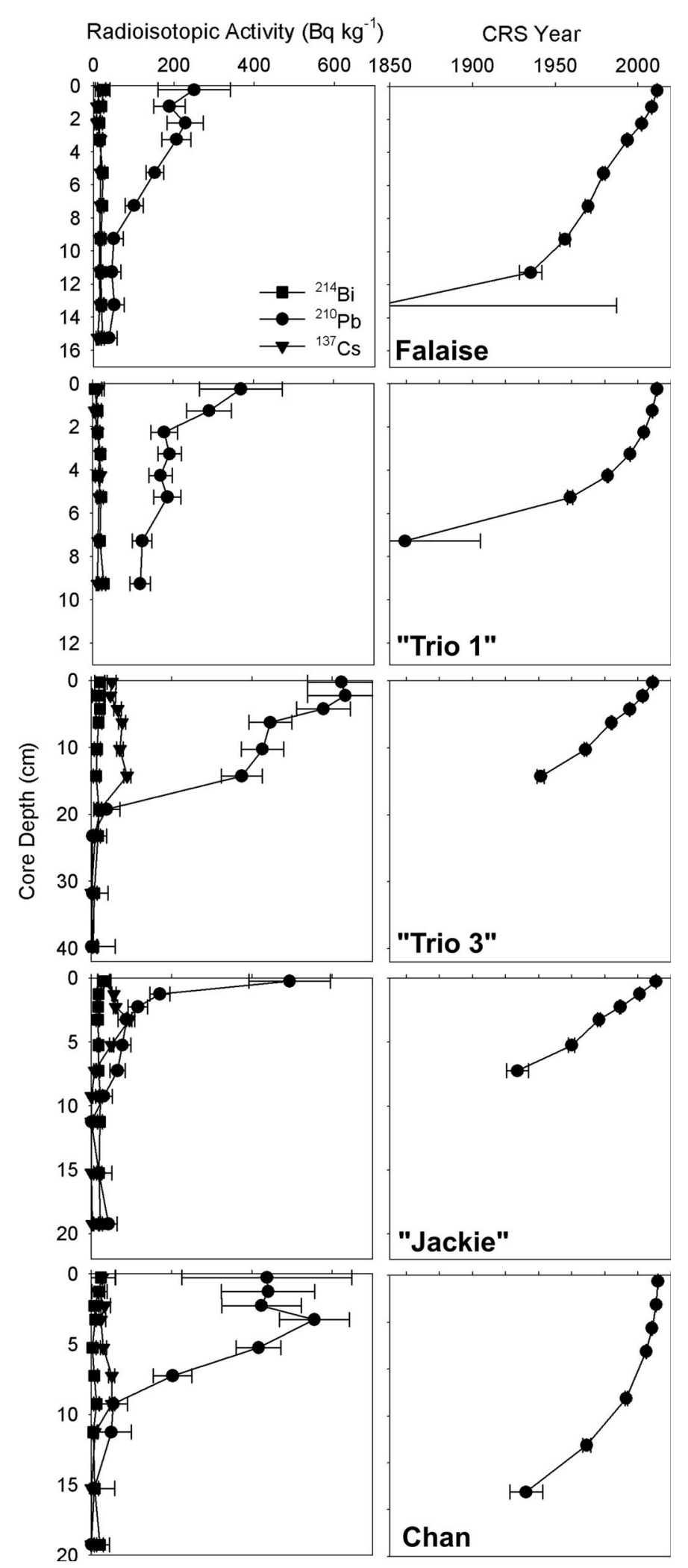


Fig. 3 Sedimentary record of total mercury concentration (per gram dry sediment weight) and Landsat-derived lake surface area for Falaise Lake, Northwest Territories, Canada

Fig. 4 Sedimentary record of total mercury concentration (per gram dry sediment weight) and Landsat-derived lake surface area for $\mathbf{a}$ Trio 1 and b Trio 3 lakes, Northwest Territories, Canada. The "Trio Lakes" are located close together, but have drastically different histories of recent expansion (Fig. 1, Table 1)
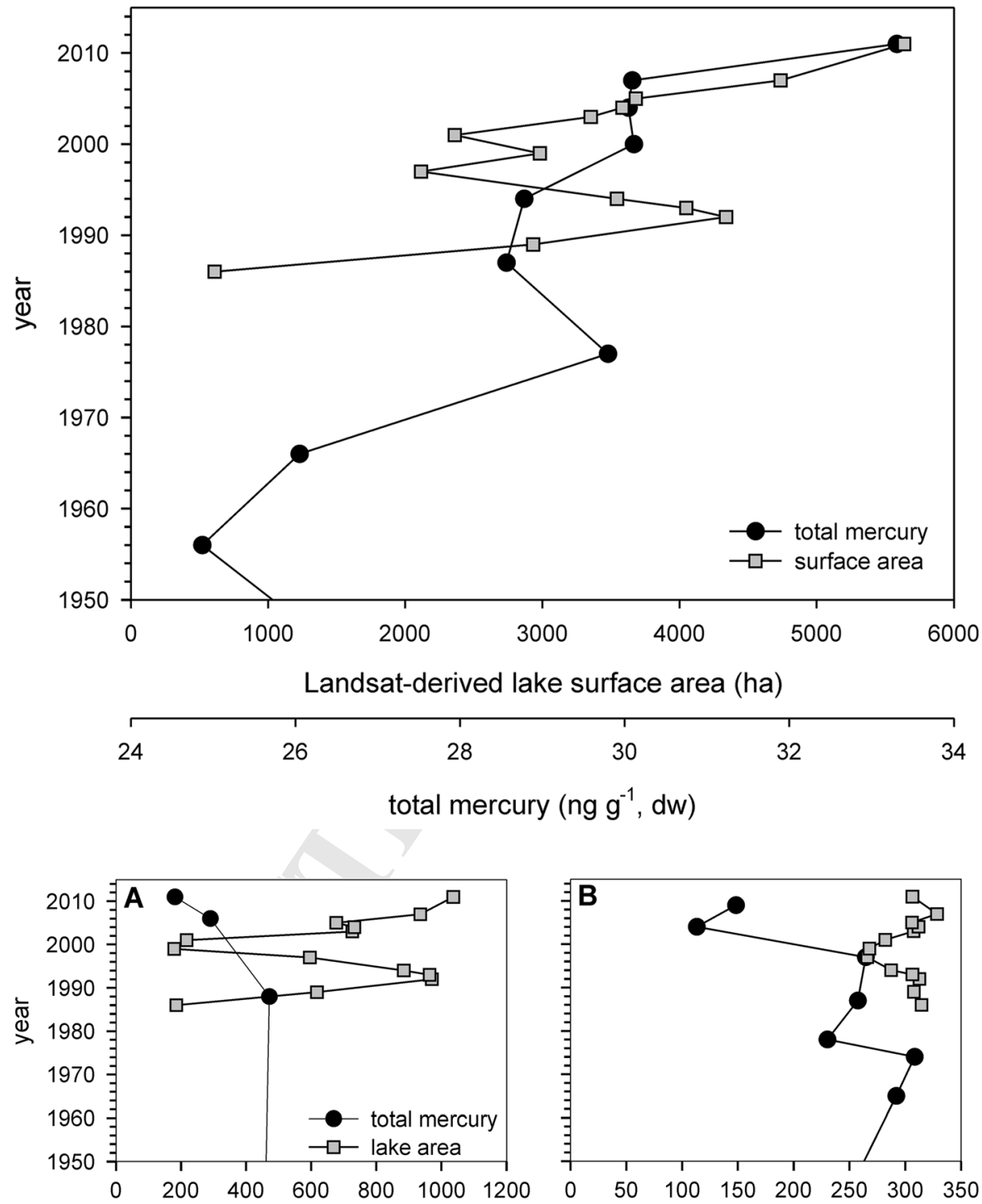

Landsat-derived lake surface area (ha)

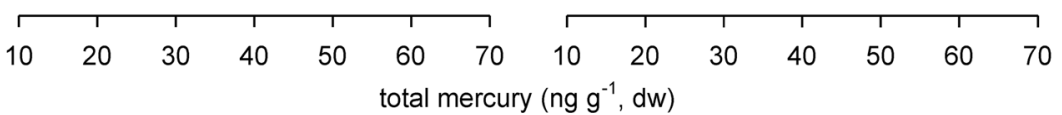

expansion in the late 1980 s, after which it increased through to the top of the core (2010) (Fig. 6a). The THg flux increased from $\sim 1800 \mathrm{ng} \mathrm{m}^{-2}$ year $^{-1}$ in $\sim 1980$ to $\sim 3000 \mathrm{ng} \mathrm{m}^{-2}$ year $^{-1}$ in the surface sediments (Fig. 6a). Mercury flux in "Trio 1" Lake remained low throughout the record, and increased from $\sim 1930$ until $\sim 1990$, after which it was constant until the uppermost (surface) sediment interval, where it decreased (Fig. 6b). The sedimentation rate in Lake "Trio 3" was the lowest of the sediment cores modelled in the study, and similarly $\mathrm{THg}$ flux was also low throughout the period for which sedimentation rate was estimated (since $\sim 1960$ ) (Fig. 6c). During this period the flux of mercury did not change markedly (Fig. 6c). Mercury flux and sedimentation rate in "Jackie" Lake increased rapidly from the bottom of the core, which continued over the recent period of rapid lake expansion (Fig. 6d). The THg flux in "Jackie" Lake was of the highest magnitude of the sediment cores from the five study

\begin{tabular}{|l|lll|}
\hline & Journal : Medium 10933 & Dispatch : 20-11-2018 & Pages : $\mathbf{1 0}$ \\
Article No. : $\mathbf{6 3}$ & $\square \mathrm{LE}$ & $\square$ TYPESET \\
& MS Code : JOPL-D-17-00061 & $\cup_{\mathrm{CP}}$ & $\searrow$ DISK \\
\hline
\end{tabular}



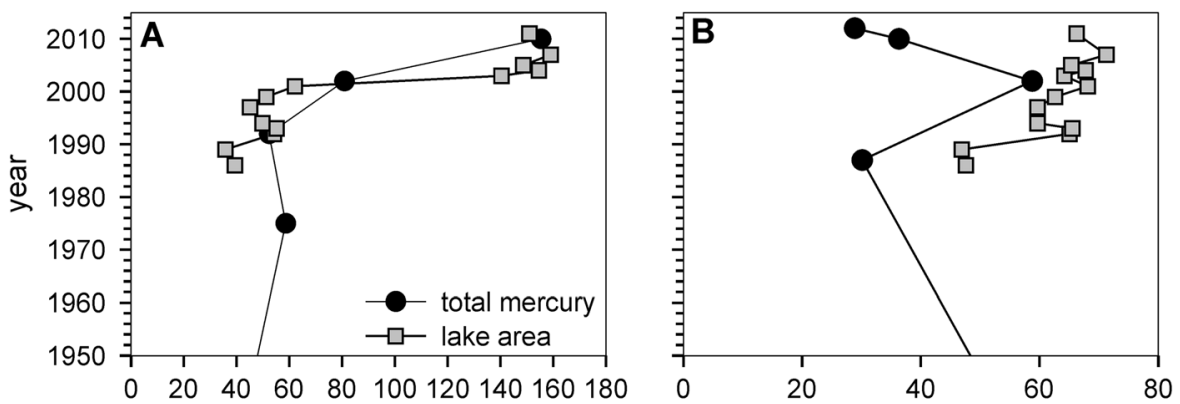

Landsat-derived lake surface area (ha)

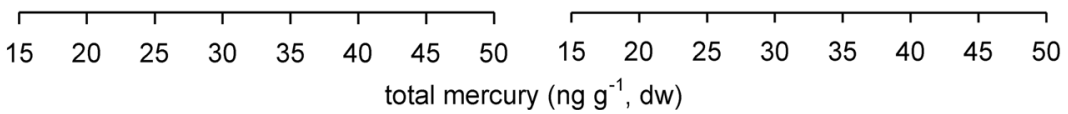

Fig. 5 Sedimentary record of total mercury concentration (per gram dry sediment weight) and Landsat-derived lake surface area for a "Jackie Lake" (unofficial name) and b Chan Lake, Northwest Territories, Canada

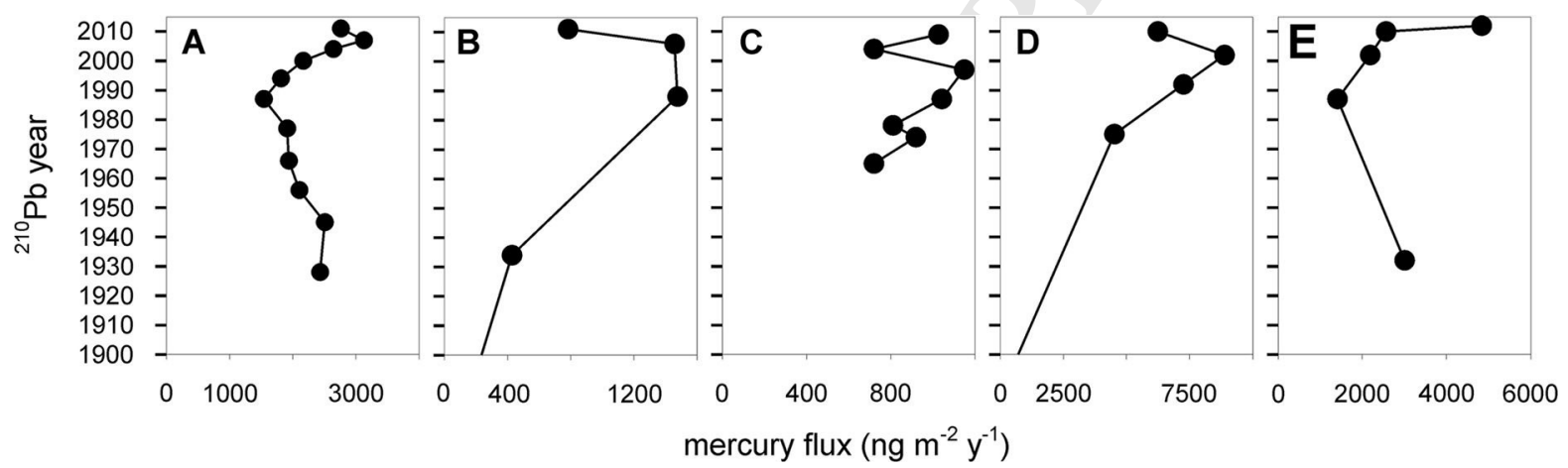

Fig. 6 Total mercury flux to the sediments (per gram dry weight, per square meter, per year) for a Falaise, b "Trio 1", c "Trio 3", d "Jackie", and e Chan lakes, in the Mackenzie Bison Sanctuary, Northwest Territories, Canada

280 lakes, with the surface sediments recording a mercury 281 flux of $\sim 7500 \mathrm{ng} \mathrm{m}^{-2}$ year $^{-1}$ (Fig. 6d). In Chan 282 Lake THg flux decreased slightly between $\sim 1930$ 283 and the late 1980s, after which it increased through to 284 the surface sediment intervals, consistent with the 285 small magnitude lake area increase (Fig. 6e). The 286 mercury flux estimates for the smaller lakes were of a 287 higher magnitude than the larger study lakes in the 288 study (Fig. 6).

\section{Discussion}

290 Is landscape flooding releasing mercury to lakes?

291 The potential for mercury stored in vegetation and 292 soils surrounding the lakes to be released following 293 flooding has been well documented (St. Louis et al.
2001, 2004; Roy et al. 2009; Teisserenc et al. 2014). However, most studies on mercury release in largerscale lake ecosystems have been due to anthropogenic impoundment for hydroelectric generation, and not due to natural landscape flooding. Natural impoundment, such as through the bio-engineering activities of beavers, are also a source of mercury to aquatic ecosystems (Roy et al. 2009), though the magnitude of impoundment from these actions is smaller. The recent lake area changes of Falaise Lake are correlated with increased total mercury, though the magnitude of the increase is small (Fig. 3). Similarly, total mercury in "Jackie" Lake, a much smaller ecosystem, has increased coincident with recent lake expansion (Fig. 5a). In "Trio 1" Lake, which has undergone the second greatest increase in surface area of the study lakes, total mercury has decreased over the recent past (Fig. 4a). The highest overall

\begin{tabular}{|l|lll|}
\hline & Journal : Medium 10933 & Dispatch : 20-11-2018 & Pages : $\mathbf{1 0}$ \\
Article No. : $\mathbf{6 3}$ & $\square$ LE & $\square$ TYPESET \\
MS Code : JOPL-D-17-00061 & $\checkmark_{\mathrm{CP}}$ & $\checkmark$ DISK \\
\hline
\end{tabular}


312 concentration of total mercury in the sediments of the 313 five study lakes was recorded in Lake "Trio 3" which 314 has not expanded recently (Fig. 4b). In Chan Lake, 315 which has increased in surface area moderately 316 compared to the other lakes (51\%), there was no 317 concurrent, directional increase in total mercury 318 concentration in the sediments (Fig. 5b). Sedimentary 319 mercury concentrations found throughout the profiles of all five sediment cores analyzed in this study are well below the sediment quality guidelines for the protection of aquatic life set at $170 \mathrm{ng} \mathrm{g}^{-1}$ by the Canadian Council of Ministers for the Environment (CCME 1999), and the range of values are similar to those found in other studies of subarctic lakes in Canada (Lockhart et al. 1995, 1998; Muir et al. 2009; Brazeau et al. 2013).

Increases in fluxes of mercury to the sediment correspond relatively closely to the timing of the recent lake expansion in Falaise and "Jackie" lakes, as well as in Chan Lake, which increased marginally in area. Despite these increasing mercury flux trends, the absolute values recorded are low, at least an order of magnitude less than lakes in northern Scotland, for example (Yang and Rose 2003). The highest flux values (Chan and "Jackie" lakes) were similar to the lowest values documented for undisturbed sites from (22 northern Canada (Lockhart et al. 1995), western Greenland (Bindler et al. 2001) and Scandinavia (Renberg 1986; Verta et al. 1989). Both the mercury concentration and flux data suggest that landscape flooding in the Great Slave Lowlands region has not resulted in the release of large amounts of total mercury to the sediments of impacted lake ecosystems.

The variable trend of mercury change, as well as the small magnitude of increase in both concentration and flux in those sites that are recording increases, contrasts with the well-documented enrichment of mercury in lake water and sediments following reservoir impoundment (Teisserenc et al. 2014). There are several reasons why this may be the case. Though the persistence of recent expansion is unique over the last several 100 years, these shallow basins are undoubtedly wetted periodically during snowmelt or periods of heavy precipitation. This would result in relatively consistent and regular leaching of mercury into the lake, as opposed to soils in reservoir impoundments that have been building up inorganic mercury over long timescales, which are then incorporated into lakewater and sediment rapidly, and in bulk. In addition, the composition of the soils could result in conversion to gaseous $\mathrm{Hg}^{0}$, which would be lost to the atmosphere, and not transported to the lake sediments (Poulin et al. 2016), and thus detailed sampling of local soil properties would be helpful for understanding mobilization and transformation properties. A second confounding factor may be the regular occurrence of fire in this region, which burns soil organic matter reserves and depletes soil mercury concentrations, also through release of gaseous mercury (Mailman and Bodaly 2005; Friedli et al. 2003). The burning of land prior to impoundment has been suggested as a mechanism for decreasing methylmercury production, through the loss of inorganic mercury (Mailman et al. 2006). Fire regime is a critically important control on vegetation structure within subarctic boreal regions (Johnson 1979), and its influence may extend to landscape mercury cycling as well. Fire return intervals are projected to decrease in the Great Slave region as a result of climate warming (Boulanger et al. 2014), and historical fire frequency may be higher in the Northwest Territories region than in eastern Canada where most of the studies of impoundment-driven mercury enrichment have occurred (Bergeron et al. 2004).

Total organic content (TOC) in the sediments of all of the lakes is relatively low $\sim 20-30 \%$, and did not change as a result of recent flooding (Korosi et al. 2017). Non-peat soils in the Great Slave Lowlands region, derived from Glacial Lake McConnell sediments (Smith 1994) tend to have a high proportion of clay and are relatively low in organic carbon (Ecosystem Classification Group 2009), in comparison to nearby areas such as the Tathlina and Kakisa lake watersheds to the west and south (TOC averages 40-50\%), where strong increases in mercury have been reported (Korosi et al. 2015). The concentrations of mercury in uncontaminated soil samples were measured at $55 \mathrm{ng} \mathrm{g}^{-1}$ in both the $\mathrm{B}$ and $\mathrm{C}$ horizons of brunisolic samples from near Fort Providence, less than $70 \mathrm{~km}$ from Falaise Lake (McKeague and Kloosterman 1974). This suggests Great Slave Plains and Lowlands soils derived from Glacial Lake McConnell sediments are likely naturally low in mercury. Importantly, the local distribution of sporadic permafrost in the region is not well documented. Frozen ground may play a role in influencing the movement of mercury in soils, by limiting mobility, 
410 and future thaw could result in altered mercury 411 availability, especially during fire events (Turetsky 412 et al. 2006).

It is important to note that throughout this study we have focused on reconstructing the history of total mercury changes in these lake ecosystems through sediment records. We have not reconstructed changes in methylmercury, the most toxic and bioaccumulative form of mercury, as historical trends cannot be reliably reconstructed from lake sediment records. There exists the potential for landscape flooding in the region to alter rates of methylation and demethylation, particularly if peatlands are inundated (Heyes et al. 2000), and increased deposition of mercury is not necessarily required for methylmercury to enter and accumulate in foodwebs (Bodaly and Fudge 1999). As changing methylation activity would not be obvious from sedimentary profiles of total mercury, further study is needed before we can definitively say that expansion has not altered the mercury cycling and availability in these lakes.

\section{Conclusions}

The recent, extensive landscape flooding that has occurred in the Great Slave Lowlands, including the Mackenzie Bison Sanctuary, resulted in increases in total mercury and mercury flux in the sediments from two recently flood lakes, though the magnitude of these increases was small ( $\sim 25-33 \mathrm{ng} \mathrm{g}^{-1}$ in Falaise Lake, and $\sim 25-45 \mathrm{ng} \mathrm{g}^{-1}$ in "Jackie" Lake). In another flooded site, no increase in total mercury was observed. Total mercury concentrations in sediments in all of the lakes studied in the region are well below Canada's sediment quality guidelines, set at $170 \mathrm{ng} \mathrm{g}^{-1}$. The potential for landscape flooding to have resulted in changes in mercury cycling, including altered rates of methylation, remains an important knowledge gap that requires future study.

Acknowledgements The authors thank the community of Fort Providence for their support, especially Louis Lacorne, Eric Nadli, and George Nadli, for assistance in the field. This research was funded by the Cumulative Impact Monitoring Program (Government of the Northwest Territories), the W. Garfield Weston Foundation (postdoctoral fellowship to JRT), the Brock University Chancellor's Chair for Research Excellence (MFJP), and the Natural Sciences and Engineering Research Council of Canada (Discovery Grants to MFJP and JMB, Northern Supplement to MFJP and a PDF to JBK).

\section{References}

Bergeron Y, Flannigan M, Gauthier S, Leduc A, Lefort P (2004) Past, current and future fire frequency in the Canadian boreal forest: implications for sustainable forest management. Ambio 33:356-360

Bindler R, Renberg I, Appleby PG, Anderson NJ, Rose NL (2001) Mercury accumulation rates and spatial patterns in lake sediments from west Greenland: a coast to ice margin transect. Environ Sci Technol 35:1736-1741

Bodaly RA, Fudge RJP (1999) Uptake of mercury by fish in an experimental boreal reservoir. Arch Environ Contam Toxicol 37:103-109

Bodaly RA, Hecky RE, Fudge RJP (1984) Increases in fish mercury levels in lakes flooded by the Churchill River diversion, northern Manitoba. Can J Fish Aquat Sci 41:682-691

Bodaly RD, Jansen WA, Majewski AR, Fudge RJP, Strange NE, Derksen AJ, Green DJ (2007) Postimpoundment time course of increased mercury concentrations in fish in hydroelectric reservoirs of northern Manitoba, Canada. Arch Environ Contam Toxicol 53:379-389

Boulanger Y, Gauthier S, Burton PJ (2014) A refinement of models projecting future Canadian fire regimes using homogeneous fire regime zones. Can J For Res 44:365-376

Brazeau ML, Poulain AJ, Paterson AM, Keller WB, Sanei H, Blais JM (2013) Recent changes in mercury deposition and primary productivity inferred from sediments of lakes from the Hudson Bay Lowlands, Ontario, Canada. Environ Pollut 173:52-60

Canadian Council of Ministers of the Environment (1999) Canadian sediment quality guidelines for the protection of aquatic life: mercury. In: Canadian environmental quality guidelines, 1999. Canadian Council of Ministers of the Environment, Winnipeg

Carroll ML, Townshend JRG, DiMiceli CM, Loboda T, Sohlberg RA (2011) Shrinking lakes of the Arctic: spatial relationships and trajectory of change. Geophys Res Lett 38:1-5. https://doi.org/10.1029/2011gl049427

Craig BG (1965) Glacial Lake McConnell, and the surficial geology of parts of Slave River and Redstone River mapareas District of Mackenzie. Geol Surv Can Bull 122

Ecosystem Classification Group (2009) Ecological regions of the northwest territories-Taiga plains. Department of Environment and Natural Resources, Government of the Northwest Territories, Yellowknife

Friedli HR, Radke LF, Lu JY, Banic CM, Leaitch WR, MacPherson JI (2003) Mercury emissions from burning of biomass from temperate North American forests: laboratory and airborne measurements. Atmos Environ 37:253-267

Glew JR (1988) A portable extruding device for close interval sectioning of unconsolidated core samples. J Paleolimnol $1: 235-239$

Glew JR (1989) A new trigger mechanism for sediment samplers. J Paleolimnol 2:241-243

Hall BD, St. Louis VL (2004) Methylmercury and total mercury in plant litter decomposing in upland forests and flooded landscapes. Environ Sci Technol 38:5010-5021

\begin{tabular}{|l|lll|}
\hline & Journal : Medium 10933 & Dispatch : 20-11-2018 & Pages : $\mathbf{1 0}$ \\
Article No. : $\mathbf{6 3}$ & $\square$ LE & $\square$ TYPESET \\
MS Code : JOPL-D-17-00061 & $\checkmark_{\mathrm{CP}}$ & $\checkmark$ DISK \\
\hline
\end{tabular}


Hall BD, Rosenberg DM, Wiens AP (1998) Methyl mercury in aquatic insects from an experimental reservoir. Can J Fish Aquat Sci 55:2036-2047

Hall BD, St. Louis V, Rolfhus KR, Bodaly RA, Beaty KG, Paterson MJ, Cherewyk KP (2005) Impacts of reservoir creation on the biogeochemical cycling of methyl mercury and total mercury in boreal upland forests. Ecosystems $8: 248-266$

Heyes A, Moore TR, Rudd JW, Dugoua JJ (2000) Methyl mercury in pristine and impounded boreal peatlands, Experimental Lakes Area, Ontario. Can J Fish Aquat Sci 57:2211-2222

Johnson EA (1979) Fire recurrence in the subarctic and its implications for vegetation composition. Can $\mathrm{J}$ Bot 57:1374-1379

Korosi JB, McDonald J, Coleman KA, Palmer MJ, Smol JP, Simpson MJ, Blais JM (2015) Long-term changes in organic matter and mercury transport to lakes in the sporadic discontinuous permafrost zone related to peat subsidence. Limnol Oceanogr 60:1550-1561

Korosi JB, Thienpont JR, Pisaric MFJ, deMontigny P, Perreault JT, McDonald J, Simpson MJ, Armstrong T, Kokelj SV, Smol JP, Blais JM (2017) Broad-scale lake expansion and flooding inundates essential wood bison habitat. Nat Commun 8:14510. https://doi.org/10.1038/ncomms14510

Larter NC, Sinclair ARE, Ellsworth T, Nishi J, Gates CC (2000) Dynamics of reintroduction in an indigenous large ungulate: the wood bison of northern Canada. Anim Conserv 4:299-309

Lockhart WL, Wilkinson P, Billeck BN, Hunt RV, Wagemann R, Brunskill GJ (1995) Current and historical inputs of mercury to high-latitude lakes in Canada and to Hudson Bay. Water Air Soil Pollut 80:603-610

Lockhart WL, Wilkinson P, Billeck BN, Danell RA, Hunt RV, Brunskill GJ, Delaronde J, St. Louis VL (1998) Fluxes of mercury to lake sediments in central and northern Canada inferred from dated sediment cores. Biogeochemistry 40:163-173

Lockhart WL, Macdonald RW, Outridge PM, Wilkinson P, DeLaronde JB, Rudd JWM (2000) Tests of the fidelity of lake sediment core records of mercury deposition to known histories of mercury contamination. Sci Total Environ 260:171-180

Mailman M, Bodaly D (2005) Total mercury, methyl mercury, and carbon in fresh and burned plants and soil in Northwestern Ontario. Environ Pollut 138:161-166

Mailman M, Stepnuk L, Cicek N, Bodaly RD (2006) Strategies to lower methyl mercury concentrations in hydroelectric reservoirs and lakes: a review. Sci Total Environ 368:224-235

McKeague JA, Kloosterman B (1974) Mercury in horizons of some soil profiles in Canada. Can J Soil Sci 54:503-507

Morrison KA, Thérien N (1991) Experimental evaluation of mercury release from flooded vegetation and soils. Water Air Soil Pollut 56:607-619
Muir DCG, Wang X, Yang F, Nguyen N, Jackson TA, Evans MS, Douglas M, Kock G, Lamoureux S, Pienitz R, Smol JP (2009) Spatial trends and historical deposition of mercury in eastern and northern Canada inferred from lake sediment cores. Environ Sci Technol 43:4802-4809

Parsekian AD, Jones BM, Jones M, Grosse G, Anthony W, Katey M, Slater L (2011) Expansion rate and geometry of floating vegetation mats on the margins of thermokarst lakes, northern Seward Peninsula, Alaska, USA. Earth Surf Process Landf 36:1889-1897

Poulin BA, Aiken GR, Nagy KL, Manceau A, Krabbenhoft DP, Ryan JN (2016) Mercury transformation and release differs with depth and time in a contaminated riparian soil during simulated flooding. Geochim Cosmochim Acta 176:118-138

Renberg I (1986) Concentration and annual accumulation values of heavy metals in the lake sediments: their significance in studies of the history of metal pollution. Hydrobiologia 143:379-385

Roy V, Amyot M, Carignan R (2009) Beaver ponds increase methylmercury concentrations in Canadian shield streams along vegetation and pond-age gradients. Environ Sci Technol 43:5605-5611

Smith DG (1994) Glacial Lake McConnell: paleogeography, age, duration, and associated river deltas, Mackenzie River basin, western Canada. Quat Sci Rev 13:829-843

St. Louis VL, Rudd JWM, Kelly CA, Hall BD, Rolfhus KR, Scott KJ, Lindberg S, Dong W (2001) Importance of the forest canopy to fluxes of methyl mercury and total mercury to boreal ecosystems. Environ Sci Technol 35:3089-3098

St. Louis VL, Rudd JW, Kelly CA, Bodaly RA, Paterson MJ, Beaty KG, Hesslein RH, Heyes A, Majewski AR (2004) The rise and fall of mercury methylation in an experimental reservoir. Environ Sci Technol 38:1348-1358

Teisserenc R, Lucotte M, Canuel R, Moingt M, Obrist D (2014) Combined dynamics of mercury and terrigenous organic matter following impoundment of Churchill Falls Hydroelectric Reservoir, Labrador. Biogeochemistry 118:21-34

Turetsky MR, Harden JW, Friedli HR, Flannigan M, Payne N, Crock J, Radke L (2006) Wildfires threaten mercury stocks in northern soils. Geophys Res Lett 33:L16403. https://doi. org/10.1029/2005GL025595

Verta M, Tolonen K, Simola H (1989) History of heavy metal pollution in Finland as recorded by lake sediments. Sci Total Environ 87:1-18

Yang H, Rose NL (2003) Distribution of mercury in six lake sediment cores across the UK. Sci Total Environ 304:391-404

\section{Publisher's Note}

Springer Nature remains neutral with regard to jurisdictional claims in published maps and institutional affiliations.

\begin{tabular}{|l|lll|}
\hline & Journal : Medium 10933 & Dispatch : 20-11-2018 & Pages : 10 \\
Article No. : 63 & $\square$ LE & $\square$ TYPESET \\
MS Code : JOPL-D-17-00061 & $\checkmark$ CP & $\checkmark$ DISK \\
\hline
\end{tabular}

